\title{
SEGURANÇA PÚBLICA E DEMOCRACIA: FATORES HISTÓRICOS E SOCIOLÓGICOS DA DINÂMICA JURÍDICA E JUDICIAL NO BRASIL
}

\author{
Lívio Silva de Oliveira ${ }^{1}$ \\ Gabriel Guerra Câmara ${ }^{2}$ \\ Geverson Aparicio Ferrari ${ }^{3}$
}

\begin{abstract}
Resumo: O objetivo deste texto é discutir o campo da Segurança Pública no Brasil, enquanto a atividade estatal que apresenta resistências no processo de estabelecimento de uma justiça de transição no Brasil, a qual efetive um controle social democrático. Metodologicamente, realizou-se uma revisão da literatura, de corte histórico, sobre a temática da segurança pública, demonstrando-se, a partir do acúmulo de estudos nessa área, realizados após a redemocratização, que este é um campo institucional resistente quanto ao estabelecimento de uma nova maneira de atuação, voltada para uma sociedade de regras democráticas. Auxiliado pela Sociologia das Conflitualidades do espaço social, demonstra-se como a segurança pública vivencia tensões no sentido da reorganização do paradigma tradicional de funcionamento dessa atividade no país, que passa aos poucos a admitir inovações e reordenações. Nesse sentido, há iniciativas que buscam produzir novas orientações para as instituições integrantes desse sistema, ancoradas em um longo debate dos movimentos sociais e acadêmico, em especial sobre o papel das polícias militares nesse contexto. A pauta da desmilitarização das polícias, as inovadoras políticas públicas do setor dos últimos dez anos, embora com avanços e retrocessos, e a formulação da noção de Segurança Cidadã, são indicativas desse processo de mudança social e institucional no contexto latino-americano.
\end{abstract}

Palavras-chave: Segurança Pública; Polícia; Subcidadania; Segurança Cidadã.

Abstract: The objective of this text is to discuss the field of Public Security in Brazil, while the state activity that presents resistance in the process of establishing a transitional justice in Brazil, which has effective democratic social control. Methodologically, a literature review was carried out, of historical cut, on the subject of public security, demonstrating, based on the accumulation of studies in this area and done after redemocratization, that this is a resistant institutional field for the establishment of a new way of acting, aimed at a society of democratic rules. Aided by the Sociology of Conflictualities of the social space, demonstrates how the public security experiences tensions towards the reorganization of the traditional paradigm of operation of this activity in the country, which gradually allows for innovations and reordering. In this sense, there are initiatives that seek to produce new orientations for the institutions that are part of this system, anchored in a long debate of social and academic movements, in particular on the role of military police in this context. The demilitarization of

\footnotetext{
${ }^{1}$ Doutorando e mestre em Sociologia pela Universidade Federal do Rio Grande do Sul. Pesquisador do Grupo de Pesquisa Violência e Cidadania (IFCH/UFRGS) e membro da rede de pesquisadores do Laboratório de Etnografia Metropolitana (IFCS/UFRJ). Especialização em Sociologia Política e Cultura pela PUC-RIO. Bacharel em Ciências Sociais/ Sociologia pela Universidade Candido Mendes.

${ }^{2}$ Bacharel em Ciências Sociais (UFRGS), Mestre e Doutorando em Sociologia (PPGS/UFRGS), membro do Grupo de Pesquisa Violência e Cidadania e do Grupo Magistratura, Sociedade e Política, ambos da UFRGS.

${ }^{3} 1^{\circ}$ Sargento da Brigada Militar do Estado do Rio Grande do Sul, Bacharel em Direito (UniRitter), Graduando em Filosofia (UFPel), Especialista em Segurança Pública com Cidadania (UFRGS), Mestre em Sociologia do PPGS/UFRGS, membro do Grupo de Pesquisa Violência e Cidadania, UFRGS.
} 
the police, the innovative public policies of the sector of the last ten years, although with advances and setbacks and the formulation of the notion of Citizen Security, are indicative of this process of social and institutional change in the Latin American context.

Keywords: Public security; Police; Undercitizenship; Citizen Security.

\section{Ditadura Civil-Militar e Segurança Pública no Brasil: heranças}

O golpe de trinta e um de março de 1964 deu início à ditadura civil-militar no Brasil, que se estendeu por um período de vinte e um anos (1964-1985), teve motivações externas e internas ao território brasileiro. $\mathrm{O}$ evento externo referente à época do acontecimento é, em especial, a bipolaridade entre os Estados Unidos da América e a União Soviética, enquanto potencias vitoriosas da II Guerra Mundial (1939-1945), marcada pela disputa da hegemonia político-ideológica mundial, a qual acarretou uma série de conflitos e de movimentos revolucionários periféricos, sempre equilibrados e acompanhados pelo medo da deflagração de um conflito armado em escala global, que envolvesse os dois países. Essa disputa denominou-se Guerra Fria, em virtude da ausência de um conflito armado direto entre eles (HOBSBAWN, 1996). O momento de maior tensão dessa disputa foi a Crise dos Mísseis, em Cuba, em 1962, onde houve uma possibilidade real de deflagração de um confronto armado, porém, finalizado com o recuo de ambos os lados.

Esse cenário internacional influenciou disputas políticas internas em alguns continentes, por se tratar de um período de alinhamento político-ideológico: sendo a favor de um, era-se contra o outro. No Brasil, não foi diferente. A deposição do presidente João Goulart na data citada, por ser identificado, exageradamente, como um presidente de orientação comunista, demonstrou os conflitos políticos de interesses dentro do país, como reflexos da conjuntura externa (DREIFUSS, 1981; FICO, 2004). No mesmo período, Argentina, Chile, Paraguai e Uruguai, entre outros, também experimentaram ditaduras, se relacionando, cada um a seu modo, com essa conjuntura de guerra fria.

É válido lembrar que a própria posse e assunção pelo cargo de Presidente da República por João Goulart foi marcada por idas e vindas. A posse de Goulart foi possível, em grande parte, pela resistência liderada pelo então Governador do Estado do Rio Grande do Sul, Leonel Brizola, no levante que ficou conhecido como a Campanha da Legalidade, realizado em 1961. Na ocasião, Brizola se aquartelou no Palácio Piratini, sede do governo estadual, com seus partidários e suas polícias, tanto a polícia civil quanto a Brigada Militar ${ }^{4}$, forçando o III Exército a negociar e, posteriormente, aderir à campanha pela posse

\footnotetext{
${ }^{4}$ Nome específico da Polícia Militar do Estado do Rio Grande do Sul.
} 
presidencial (ALMEIDA, 1997). Porém, a posse de Jango, no mesmo ano, se deu com seus poderes presidenciais esvaziados. O poder efetivo como presidente seria restaurado apenas pelo plebiscito de 1963, que referendou o presidencialismo como sistema de governo brasileiro, o qual perdura até hoje.

O golpe teve apoio de setores conservadores da sociedade e foi levado ao cabo pelos militares. Os militares se alternaram nos cargos de presidentes da República, não perdendo o caráter ditatorial do regime. O Ato Institucional número 5 (AI-5), de 1968, marca definitivamente o fechamento do regime, com perseguições políticas, exílios de artistas e intelectuais, etc. A Doutrina de Segurança Nacional (DSN), estabelecida pelo governo, seguiu parâmetros norte-americanos, a fim de conter os avanços comunistas no Cone Sul, ponto geográfica e estrategicamente interessante para o Governo de Washington (FICO, 2004). A proposta estadunidense era de que os militares seriam o bastião contra os grupos comunistas nos países da América Latina, oferecendo ajuda logística e tática, chegando a ser proposto, no governo Einsenhower ${ }^{5}$, que as forças armadas desses países tomassem forma de guerrilhas, mais ágeis, para combater o inimigo comunista e fazer a segurança pública (FICO et al, 2008). Nesse sentido, podemos considerar a DSN como decisiva no processo de conformação institucional e de militarização da segurança pública no Brasil, por caracterizar futuramente, e de forma específica, o modelo cultural de policiamento que será adotado e, juntamente com isso, os paradigmas sobre a criminalização de condutas de grupos determinados da sociedade brasileira.

Historicamente, a atividade de polícia surgiu desde que o homem se organizou em grupo social e subordinou-se a um poder ou governo, a fim de promover o bem e a segurança coletiva dos indivíduos.

Em se tratando do campo da Segurança Pública no Brasil, cabe destacar que as polícias militares, as quais até então tinham papel secundário na segurança, e eram subordinadas ao Exército através da Inspetoria Geral das Polícias Militares, começaram a atuar nas ruas, desde o controle do tráfego até a circulação de pessoas com vistas à manutenção da ordem pública, incorporando as atribuições das guardas civis, extintas no ano de $1969^{6}$.

A militarização da segurança pública foi, futuramente, decisiva para a criação de um processo social de criminalização de manifestações indesejadas, com o uso abusivo da

\footnotetext{
${ }^{5}$ Dwight D. Eisenhower, 34º presidente dos EUA (1953-1961).

Fonte: http://www.whitehouse.gov/about/presidents/dwightdeisenhower

${ }^{6}$ Decreto-Lei federal no 1.072 de 30 de Dezembro de 1969.
} 
violência física como norma particular de ação (TAVARES-DOS-SANTOS, 2009), que não se orienta pelos princípios democráticos, mas por uma cultura institucional autoritária, criada, em grande medida, - porém não exclusivamente - no período ditatorial, e amparada em valores igualmente autoritários da sociedade brasileira. Nesse sentido, esse processo de militarização teve o efeito perverso de tirar o foco da segurança do cidadão e priorizar a defesa do Estado. Com esse grande dimensionamento do Estado na perspectiva militar, o policiamento ostensivo passa a fazer o papel de polícia de manutenção da ordem enquanto valor universal, ou seja, uma polícia política que reprime aqueles que são considerados como inimigos e/ou opositores do governo vigente ou do Estado, em detrimento da perspectiva de segurança pública de caráter civil, que tem como prioridade a defesa dos interesses do cidadão. Além disso, parece pautar a ação das polícias militares a ideia de inimigo, que ganha contornos graves, uma vez que a perspectiva belicista implica na eliminação física do inimigo, não sendo raro no Brasil casos de assassinatos de pessoas pelas forças do Estado. David Bayley (2001) aponta esse aspecto:

[...] a polícia está para o governo, assim como a lâmina está para a faca. $\mathrm{O}$ caráter do governo e a ação policial são virtualmente indistinguíveis. O governo é reconhecido como autoritário quando sua Polícia é repressora e como democrática quando sua Polícia é controlada. Não é por coincidência que os regimes autoritários são chamados de "Estados policiais". A atividade policial é crucial para se definir a extensão prática da liberdade humana. Além disso, a manutenção de um controle social é fundamentalmente uma questão política. Não apenas ela define poderosamente o que a sociedade pode tornar-se, mas é uma questão pela qual os governos têm um grande interesse, porque sabem que sua própria existência depende disso. Por todas essas razões, a Polícia entra na política, querendo ou não. (BAYLEY, 2001, p. 203).

As práticas de violência empregadas pelos setores de Segurança Pública em seus procedimentos na ditadura, como a prática da tortura, prisões ilegais - sem trâmites legais e sem a habeas corpus - e execuções sumárias de opositores contra os grupos que aderiram à luta armada de oposição ao regime (OLIVEIRA, 2008), ganham uma visibilidade maior no contexto pós-redemocratização. Tais práticas foram extensivas às classes pobres da população brasileira, historicamente reprimidas pelas polícias e, também, estigmatizadas pela marginalidade e por processo de criminalização.

Essa construção histórica, que remonta a períodos muitas vezes anteriores à ditadura, vai desde o policiamento no Brasil-Colônia, realizado por particulares, que buscava reprimir revoltas de escravos e de homens livres que eram considerados inimigos da ordem, 
até a institucionalização das polícias no século XX, além de outros momentos ditatoriais, como o Estado-Novo de Getúlio Vargas, o qual também prendia e torturava. Em síntese, a atividade de policiamento no Brasil, desde os fins do século XIX, pode ser, em grande medida, "relacionada à demarcação de fronteiras entre as pessoas, os homens livres e escravos, cidadãos trabalhadores e grevistas e entre cidadãos honestos e criminosos." (NUMMER, 2010, p. 76).

\section{Estigma, Subcidadania e Polícia.}

Essas fronteiras humanas podem ser caracterizadas, no Brasil, por categorias sociais que se enquadrem em uma espécie de catálogo de suspeitos ideais de crimes (OLIVEIRA, 2010). A produção social desse catálogo baseia-se em um conjunto de desvantagens que incidem em um indivíduo. Os apontamentos sobre o estigma social de Erving Goffman nos servem de base para compreendermos, de uma perspectiva sociológica, como se dá essa categorização. O estigma pode ser uma marca física ou social, o que implica em uma carreira moral daquele que é estigmatizado. Esse indivíduo se torna desacreditado ou desacreditável por meio de seu estigma, frente aos demais da sociedade, por serem atribuídos a ele valores depreciativos que acarretam uma série de desvantagens, individuais e/ou sociais. O estigma se configura, segundo Goffman (1978), como uma relação de poder assimétrica, na qual podemos pensar que o estigmatizado não é necessariamente humano. Quem determina o estigma, normalmente, é uma classe dominante, através da construção de um discurso que visa à estigmatização de determinada categoria social, a qual se encontra em situação de vulnerabilidade social.

Ao lançarmos luz a situações que acarretam situação de vulnerabilidade, verificamos o estigma social sobre indivíduos de determinadas classes, percebendo-se, estatisticamente, uma regularidade no perfil de marginalização e criminalização dos indivíduos que compõem esse catálogo no Brasil. Em geral, são negros/pardos, homens, jovens entre 15 e 29 anos, pobres e moradores de áreas periféricas e/ou de favelas ${ }^{7}$.

Esses espaços de pobreza, marginalizados, foram sendo estigmatizados a partir de uma reconstrução histórica de desigualdades e violências como forma de dominação por parte das elites na formação do Estado brasileiro. Ocorre, nesse processo, o abandono do Estado em

\footnotetext{
${ }^{7} \mathrm{O}$ termo pode variar de região para região do Brasil. No caso do Rio Grande do Sul, o termo mais utilizado é vila.
} 
serviços básicos, como saúde e educação, gerando uma invisibilidade social de seus moradores, ligados a preconceitos raciais e de origem social (GAMALHO, 2010).

A ideia de estigma, relacionada ao processo brasileiro, vem a reforçar o conceito de subcidadania (SOUZA, 2003), do sociólogo Jessé de Souza. Para o autor, a condição do indivíduo marginalizado é subhumanizada, tendo em vista que, dependendo da situação, uma rede invisível e simbólica não precisa ser verbalizada para ser uma questão de absolvição ou de penalização do agente social. Quando o marginalizado é vítima de um processo e o autor da agressão é de uma classe mais alta na hierarquia social, o processo pode ser arquivado ou até mesmo haja a inocência do agressor. Esse fato pode ocorrer por meio dessa relação na qual o judiciário pode considerar que há pessoas acima e há pessoas abaixo da lei, caracterizando o quadro de sub e, também, de supercidadania, evidenciando a desigualdade jurídica. Em outras palavras, o Estado brasileiro não apresenta em sua gênese e nem em seu desenvolvimento a ideia de igualdade legal a partir da condição do indivíduo como pessoa, ao contrário, se ampara, de forma quase exclusiva, em sua condição social e/ou econômica. Esse processo acarreta um quadro de gradação jurídica. Assim, a cidadania torna-se uma questão material no sentido de detenção dos meios de produção, onde a lei se configura genérica, sustentando-se apenas no aspecto formal, enquanto na prática ela é seletiva. No Brasil, o leque de desigualdades apresentados, acarretam em dimensões de vulnerabilidade das populações marginalizadas e ocasionam vulnerabilidade jurídica a essas classes. Essa situação implica diretamente no exercício ou não da cidadania, por parte do indivíduo, dimensão essa que é fundamental no processo de reconhecimento do agente social como sujeito de direitos $(\text { SOUZA, 2003) })^{8}$

É apenas esse tipo de consenso, como que corporal, pré-reflexivo e naturalizado, que pode permitir, para além da eficácia jurídica, uma espécie de acordo implícito que sugere, como no exemplo do atropelamento no Brasil, que algumas pessoas e classes estão acima da lei e outras abaixo dela. Existe como que uma rede invisível, que une desde o policial que abre o inquérito até o juiz que decreta a sentença final, passando por advogados, testemunhas, promotores, jornalistas etc., que, por meio de um acordo implícito e jamais verbalizado, terminam por inocentar o atropelador. O que

\footnotetext{
${ }^{8}$ No artigo citado, Jessé de Souza procura demonstrar como se constitui uma condição de não reconhecimento social de determinadas classes sociais brasileiras, fruto de uma naturalização da desigualdade social entre nós e decorrente de nossa situação periférica no processo da modernidade ocidental. A ideia central do autor é a de que, em sociedades periféricas como a brasileira, não se produz um compartilhamento valorativo, um consenso que perpasse igualmente as classes sociais no sentido da produção do reconhecimento social igualitário entre os diferentes grupos sociais. $\mathrm{O}$ exemplo do atropelamento é utilizado pelo autor para exemplificar como opera cotidianamente essa situação de não reconhecimento e silêncio cúmplice frente a grupos sociais determinados. No limite, é a ausência desse compartilhamento social, que reforça e reproduz desigualdades de diversos tipos, tais como desigualdades econômicas, educacionais, simbólicas, etc.
} 
liga todas essas intencionalidades individuais de forma subliminar, e que conduz ao acordo implícito entre elas, é o fato objetivo e ancorado institucionalmente do não valor humano do atropelado, posto que é precisamente o valor diferencial entre os seres humanos que está atualizado de forma articulada em todas as nossas práticas institucionais e sociais. [...] $\mathrm{O}$ que existe aqui são acordos e consensos sociais mudos e subliminares, mas por isso mesmo tanto mais eficazes, que articulam, como que por meio de fios invisíveis, solidariedades e preconceitos profundos e invisíveis (SOUZA, 2003, p. 71).

Esse processo de desumanização do estigmatizado e sua consequente subcidadania tem efeitos na atividade policial. O catálogo de suspeitos ideais, somado a particularidade da atividade policial na modernidade tardia brasileira, que se configura no limite entre viver e morrer, gerando uma decisão rápida do agente policial de quem vive e de quem morre (TAVARES-DOS-SANTOS, 2009), torna o quadro de subcidadania mais grave do ponto de vista da atuação do sistema de justiça criminal. Os policiais têm que dar pronta resposta sobre os crimes tanto para sociedade quanto para seus superiores. Com isso, a possibilidade de abuso de autoridade sobre aqueles indivíduos que se enquadrem no perfil anteriormente descrito, podendo eles ser alvo de chantagens devido ao seu estigma social, para que negociem ou confessem, forçadamente, crimes, os quais às vezes não cometeram, para que não sejam infligidos danos corporais nos mesmos (OLIVEIRA, 2010).

A relação da polícia brasileira com esse processo evidencia-se, novamente, quando da utilização dessa instituição como ferramenta de controle social justamente dessas classes sociais, a qual, muitas vezes, é legitimada por parte da população brasileira, que se ampara em exigências imediatistas, das quais o papel de polícia acaba sendo entendido de forma reduzida. O papel da polícia, nesse senso comum, é apenas o de cumprir suas expectativas implícitas de justiça, não levando em conta as múltiplas contradições decorrentes dessa situação, acarretando, assim, uma evolução instável da instituição policial para a efetivação de uma justiça de transição, a qual se efetive democrática no Brasil.

Muitos esforços empreendidos para aprimorar a atividade policial avançaram em direção à presunção de que prevenir o crime e prender criminosos eram as atribuições fundamentais da polícia. Mas essas suposições estavam baseadas mais na mitologia que cerca o policiamento do que em um apurado estudo a respeito do trabalho policial. A própria polícia perpetuou tal mito (GOLDSTEIN, 2003, p. 23).

A ideia de justiça como eliminação física do criminoso partir de um julgamento moral da sociedade, dependendo qual foi o crime cometido (MISSE, 2010) potencializa o 
caráter bélico da militarização da segurança pública, caracterizando o campo da segurança pública, de extrema complexidade, em simplismos baseados em necessidades sociais imediatas, quando não de perspectivas particularistas direcionadas por expectativas de vingança frente ao dano sofrido.

Soma-se a esse quadro, a espetacularização do trabalho policial, levada a cabo por programas sensacionalistas nas grandes emissoras de televisão brasileira e, ainda, por recentes produções cinematográficas nacionais, tais como o filme Tropa de Elite, que veiculam a imagem do policial justiceiro/herói. Esse processo pode ter consequencias desastrosas no que tange ao direito essencial a vida, já que não leva em consideração a responsabilidade social do policial, não o compreendendo como um agente defensor da democracia e difusor dos Direitos Humanos.

Concluindo, a formação da instituição policial no Brasil remonta, também, para além do período da ditadura, e para aspectos de uma violência embrionária dentro do Estado brasileiro e da formação social do país, refutando, em parte, o argumento de que utilização da violência física e o abuso de autoridade ocorreram exclusivamente na ditadura civil-militar.

Passemos agora, após apresentar esse quadro social e cultural no qual atua a o sistema de justiça criminal brasileiro, inserido nesse sistema o subsistema da segurança pública, para as reformulações institucionais dos últimos anos no sentido de uma justiça de transição democrática nesse campo no Brasil.

\section{Tensões e reformulações atuais}

Contemporaneamente, a Segurança Pública no país vem sofrendo transformações decorrentes de dois processos sociais que se desenvolveram na segunda metade do século $\mathrm{XX}$ e nos primeiros anos do século XXI, os quais produzem modificações nos fenômenos da violência e da criminalidade, objetos de atuação institucional desse campo estatal. Em primeiro lugar, como citado anteriormente, ao final da década de 1980, o Brasil substitui, como resultado, em grande medida, das lutas sociais e políticas, o modelo ditatorial pela democracia, experimentando nesse período, paradoxalmente, o surgimento de novas modalidades criminosas e o aumento de diferentes delitos como, por exemplo, a delinquência urbana, os homicídios, o tráfico internacional de drogas e a ocorrência de conflitos nas relações intersubjetivas com desfechos fatais (ADORNO, 2002, p. 88). Ao mesmo tempo, a década de 1990 é o período de aprofundamento da globalização, fenômeno social que permite 
perceber, de forma concomitante, a ocorrência global de diversas manifestações sociais, entre elas a violência (TAVARES-DOS-SANTOS, 1999; WIEVIORKA, 1997). Nesse contexto, as análises sociológicas desse fenômeno tendem a levar em consideração a globalização enquanto um complexificador dos efeitos e características das formas de violência contemporâneas.

O sociólogo José Vicente Tavares dos Santos (1999), a partir da Sociologia das Conflitualidades, tenta dar conta dessa nova qualificação da violência, e suas possibilidades para pensar sociologicamente esse fenômeno no continente latino americano e, em especial, na sociedade brasileira. Segundo o sociólogo, a partir da globalização, ocorre a percepção, de forma concomitante, não só da violência, mas também das diversas conflitualidades sociais presentes nas relações sociais, podendo-se falar em uma perspectiva da mundialização dessas mesmas conflitualidades. As sociedades latino-americana e brasileira experimentariam um quadro mais crítico de conflitualidades sociais na medida em que esses espaços convivem com fortes processos estruturais de desigualdade socioeconômica, aprofundados ainda mais pela globalização. O fenômeno da violência assume um caráter difuso, identificando-se uma multiplicidade de formas e manifestações, tais como violência social, policial, simbólica e, mais recentemente, violência ecológica. Conceitualmente, amparado na microfísica do poder, de Michel Foucault, o autor propõe uma microfísica da violência contemporânea:

[...] as diferentes formas de violência presentes em cada um dos conjuntos relacionais que estruturam o social podem ser explicadas se compreendermos a violência como um ato de excesso, qualitativamente distinto, que se verifica no exercício de cada relação de poder presente nas relações sociais de produção do social. [...] Força, coerção e dano, em relação ao outro, enquanto um ato de excesso presente nas relações de poder - tanto nas estratégias de dominação do poder soberano quanto nas redes de micropoder entre os grupos sociais - caracteriza a violência contemporânea [...] O aumento dos processos estruturais de exclusão social pode vir a gerar a expansão das práticas de violência como norma social particular, vigente em vários grupos sociais enquanto estratégia de resolução de conflitos, ou meio de aquisição de bens materiais e de obtenção de prestígio social, significados esses presentes em múltiplas dimensões da violência social e política contemporânea (TAVARES-DOS-SANTOS, 2002, p. 17-18).

As ideias de força, coerção e dano demarcam a violência enquanto um fenômeno social desagregador e desorientador de sociabilidades primárias e secundárias, configurandose, também, uma crise do contrato social moderno. A sociedade brasileira, em específico, assiste a um dilaceramento da cidadania produzida pela cotidianidade das formas de violência, as quais, no limite, colocam em xeque as possibilidades de efetivação de uma sociabilidade 
democrática, baseadas em normas cidadãs e na participação social (TAVARES-DOSSANTOS, 2009). Produzem-se, e cruzam-se, nesse quadro de produção de desigualdades estruturais, aprofundadas pela globalização e pelo neoliberalismo, uma modernização seletiva (SOUZA, 2000), e as dinâmicas da subcidadania anteriormente descritas, e suas relações com as características específicas da cultura policial brasileira, inserida em um contexto cotidiano de violência social. Como exemplo, estatisticamente, o Brasil, do período que vai da década de 1980, chegando ao ano de 2007, alcança a marca, de forma aproximada, de um milhão de indivíduos assassinados, cifra indicadora de uma verdadeira sociedade conflituosa.

Nesse quadro de transformações sócio-políticas, econômicas e culturais, o campo da Segurança Pública começa, aos poucos, a desenvolver, como resposta a essa violência difusa e aos processos de estigmatização - que levam a criminalização e a vitimização de grupos determinados da sociedade brasileira -, projetos de reformulação, admitindo, de forma desigual e conflituosa, inovações e reorientações institucionais, as quais envolvem diversos agentes sociais, inserindo-se no desenvolvimento do que tem sido denominado, na América Latina, de paradigma da Segurança Cidadã, o qual se traduz no Brasil hoje como um novo paradigma em segurança pública (KRUCHIN, 2013, p. 41). Pretende-se, com essas modificações, uma segurança que seja parte integrante do processo de uma justiça de transição efetiva à democracia no país. Porém, essa perspectiva progressista de controle social não se desenvolve sem resistências e em um contexto social complexo e adverso:

A possibilidade de um novo Estado de Bem-Estar Social, emergindo em face da desigualdade social nas grandes metrópoles, realiza-se em meio a vicissitudes: políticas sociais de inclusão; desafios contemporâneos de acesso à ciência e às tecnologias sociais; regulação social das atividades econômicas; e proposição de alternativas de controle social. Nesse plano, são cruciais os dilemas da cidadania, tanto na democracia representativa quanto nas complementares experiências de democracia participativa. [...] Define-se uma intervenção pública nos processos sociais na forma de tecnologias sociais, ou seja, uma série de ações que modificam as relações sociais. Nessa perspectiva há indícios de um desenvolvimento da noção de segurança cidadã na América Latina, a qual supõe a construção de um controle social, formal e informal, não-violento e transcultural, preocupado com as práticas de si, emancipatórias, dos grupos e conjuntos de cidadãos e cidadãs em suas vidas cotidianas. A atitude dos agentes estatais em um processo de Segurança Cidadã precisa ser guiada pela ação comunicativa e pelo reconhecimento dos direitos e da dignidade de todos os cidadãos e cidadãs (TAVARES-DOS-SANTOS; TEIXEIRA, 2012, p. 12 e 15).

Mais ainda:

Em outras palavras, a emergência de uma noção de segurança cidadã, na perspectiva da mundialização, supõe a construção social de controle social 
democrático, mediante o qual tanto as instituições sociais de socialização - a família, a escola, as associações locais, os meios de comunicação - quanto às organizações do controle social formal - as polícias, o sistema judiciário, as instituições prisionais - reconstruam o objetivo de uma governamentalidade preocupada com as práticas de si, emancipatórias, dos conjuntos de cidadãos e cidadãs em suas vidas cotidianas, em suas trajetórias sociais e em seus sonhos de sociedade (TAVARES-DOS-SANTOS, 2009, p. 152).

A reformulação dessa atividade começa, no Brasil, concomitantemente a inserção da segurança como plataforma política de campanhas eleitorais à presidência da república. Eleito o presidente Fernando Henrique Cardoso, do PSDB, em 1994, no ano seguinte é elaborado o I Plano Nacional dos Direitos Humanos (PNDH) em 1995, criada a Secretaria Nacional de Direitos Humanos em 1997 e a Secretaria Nacional de Segurança Pública em 1998. Essa reorientação aprofunda-se institucionalmente nos dois governos Luiz Inácio Lula da Silva (2003-2010), do PT, com a elaboração, em 2007, do Sistema Único em Segurança Pública (SUSP) ${ }^{9}$ e do Fundo Nacional de Segurança Pública, culminando, nesse mesmo ano, com a elaboração e aplicação do Programa Nacional de Segurança com Cidadania, o PRONASCI, a política pública de Segurança Pública mais abrangente do Brasil até então.

Fora do âmbito governamental, houve a criação, no ano de 2006, do Fórum Brasileiro de Segurança Pública (FBSP), resultado de esforços de especialistas e agentes da segurança pública no Brasil, a fim de discutir, debater e elaborar propostas reais para a melhoria das formas de ação das corporações policiais no país ${ }^{10}$.

No campo acadêmico, a temática da Segurança Pública tem abarcado diversos estudos, os quais se dividem sobre as partes integrantes desse complexo sistema. Esse debate se inicia no Brasil no final dos anos de 1980, com o papel pioneiro do Núcleo de Estudos da Violência, da Universidade de São Paulo (USP), e se desenvolve ao longo de toda a década de 1990, aprofundando-se e abrindo seu leque de temas, os quais atualmente ocupam os pesquisadores, tais como a seletividade e a letalidade da ação policial, o modelo de policiamento comunitário, as políticas públicas de segurança pública com cidadania, a ocorrência dos homicídios, isso para ficarmos somente nos temas mais estudados. Essa temática experimentou, nos últimos anos, um crescimento exponencial de produção científica, em virtude, especialmente, da nova dimensão que os eventos delitivos e de violência assumem no Brasil após a redemocratização, em 1988.

\footnotetext{
${ }^{9}$ Segundo Freire (2009), diferentemente do SUS, o SUSP não busca a unificação do sistema, apenas a integração, com vistas na otimização dos resultados.

${ }^{10}$ Link: http://www2.forumseguranca.org.br/novo/
} 
O dado oficial, do ano de 2011, da Comissão de Aperfeiçoamento de Pessoal de Nível Superior (CAPES) aponta um número total de 8205 trabalhos, entre teses e dissertações - sem levar em conta trabalhos de conclusões de curso - nas diversas áreas de conhecimento, que analisam e dialogam, direta e indiretamente, com o campo da Segurança Pública. Exemplarmente, no ano de 2009 foram criados dois Institutos Nacionais de Ciência e Tecnologia (INCTs) voltados à temática da segurança e da violência no Brasil. Esses INCTs são redes de grupos de pesquisa que, em virtude de ocuparem-se do mesmo tema, permitem que eles trabalhem em rede, compartilhando pesquisas e resultados. São formados por redes de cooperação entre diferentes grupos e núcleos de produção de pesquisa acadêmica vinculados em grande parte às universidades brasileiras, às vezes com parcerias internacionais - relacionados com o tema da violência, da segurança pública e do sistema de justiça criminal. O INCT Democracia, Violência e Segurança Cidadã, coordenado pelo professor Sérgio Adorno, do NEV da USP, e o INCT Instituto de Estudos Comparados em Administração Institucional de Conflitos, este sendo coordenado pelo professor Roberto Kant de Lima, da Universidade Federal Fluminense (UFF), são os principais em atividade no país.

Esse conjunto de debates diagnostica a necessidade de uma reformulação do campo do controle social no Brasil, e também na América Latina de uma forma geral. A proposta da Segurança Cidadã enquanto um novo paradigma em segurança é resultado de um amplo conjunto de discussões internacionais e nacionais que colocam a necessidade da substituição progressiva dos métodos tradicionais de segurança pública, em um cenário de aprofundamento da violência na sociedade brasileira.

Nessa discussão, porém, Freire (2009) trabalha com a caracterização periódica dos paradigmas em segurança que o Brasil experimentou - e ainda experimenta - do período da ditadura civil-militar até hoje. Primeiramente, o país adota o modelo da Segurança Nacional no período de 1964-1985, substituindo-se esse modelo pela Segurança Pública com a promulgação da Constituição de 1988, e por fim, a partir dos anos 2000, desenvolve-se na América Latina o conceito de Segurança Cidadã. Cada um desses três modelos possui um núcleo paradigmático (FREIRE, 2009, p. 108) que o identifica, sendo possível caracterizá-lo e diferenciá-lo frente aos outros paradigmas. A autora adverte que as políticas públicas são orientadas por um paradigma, não se encontrando na realidade das políticas uma aplicação direta e perfeita dos pressupostos paradigmáticos de cada modelo, ainda mais em contextos de desigualdade socioeconômica. Pode-se afirmar que esse novo paradigma está orientado, do ponto de vista conceitual, para uma perspectiva preventiva da violência e da criminalidade, ao mesmo tempo em que produz uma expansão de atuação das esferas de governo e estimula 
uma mobilização da sociedade no desenvolvimento dessa mesma prevenção, podendo ser caracterizado como um modelo institucional descentralizado (KRUCHIN, 2013). Porém, é comum na realidade social brasileira a coexistência, em um mesmo contexto, de políticas públicas de perspectiva progressista assim como a ausência de alternativas ao controle social, tais como a prisão como forma de punição ${ }^{11}$ e a continuidade do combate ao tráfico de drogas a partir da perspectiva do confronto policial.

Entretanto, a situação da segurança no país, mesmo com esse quadro de reformulações, revela-se historicamente ambígua em virtude do quadro cultural que orienta, muitas vezes, as ações ligadas a essa atividade estatal. Aqui, a segurança ainda mostra-se um campo controverso na medida em que evidencia uma continuidade de métodos e visões institucionais herdados, em parte, dos governos militares, especialmente pelas polícias militares, que ficaram constitucionalmente a cargo dos estados (PINHEIRO, 1997, p. 47). Passados vinte e um anos de período ditatorial, o Brasil adota a democracia. De lá para cá, abre-se no país espaço para o surgimento de novas reivindicações, presentes em diferentes movimentos sociais, que por muito tempo foram reprimidos pelo Estado brasileiro. A sociedade civil brasileira começa, a partir da década 1990, a questionar o funcionamento de diversas instituições oficiais, entre elas a polícia, a qual, mesmo com o fim da ditadura, continua privilegiando métodos de ação repressivos utilizados naquele período. Segundo Pinheiro (1997), acreditava-se que a democracia traria o fim das relações arbitrárias entre Estado e sociedade, porém, o que se assistiu foram continuidades de métodos autoritários no campo do controle social, ligados à justiça penal e a segurança pública.

Nesse sentido, se pode pensar que o campo da Segurança Pública, em sua constituição e funcionamento, encontra barreiras e dificuldades no que se refere a influências e possíveis permeabilidades, oriundas da sociedade, em seu interior. Essas dificuldades, resultantes de um processo histórico, resumem-se em um fechamento institucional dessa atividade do Estado no Brasil.

Esse quadro de fechamento institucional começa, aos poucos, a ser tensionado pela perspectiva da Segurança Cidadã, a qual tem apresentado tendências de modificações institucionais, como, por exemplo, a constituição de políticas públicas de segurança com cidadania com foco na prevenção à violência, guiadas pela horizontalidade e complementariedade de atuação estatal - através de políticas públicas orientadas pelo

${ }^{11}$ Para estatísticas atualizadas sobre a violência e segurança pública brasileira, em especial sobre a situação prisional no Brasil, analisar o $7^{\circ}$ Anuário Brasileiro de Segurança Pública, disponível em: http://www.forumseguranca.org.br/storage/download//anuario_2013.pdf 
conceito de Estado-rede -, a municipalização da segurança pública, a reformulação do papel das polícias, influenciados pelo modelo de polícia comunitária e o debate da possibilidade de sua desmilitarização e, por fim, a criação de conselhos e fóruns participativos da sociedade civil, voltados para esse tema.

O Estado, em uma perspectiva histórica, não apresentou uma política para definir o papel de polícia, ficando aos sabores dos diferentes governos, em especial os estaduais, muitas vezes de orientações ideológicas díspares, como essas instituições estariam enquadradas nas suas políticas públicas de segurança, ou seja, essas políticas não se caracterizam como uma política de Estado, e sim de governo, causando, algumas vezes, instabilidade institucional. As greves das polícias brasileiras, nos anos de 1997, 1999 e 2001 demonstram essa situação, assim como a insatisfação dos próprios policiais com essa situação de indefinição, a qual produz certo mal-estar nas corporações (TAVARES-DOS-SANTOS, 2009).

A partir disso, a literatura indica uma tensão (FERNANDES, 2010) entre, de um lado, esse fechamento institucional e, de outro, um processo tendencial de abertura social. Essa tensão se desenvolve de forma conflituosa e não linear, por envolver diversos agentes sociais, tradicionais e novos, com diferentes perspectivas sobre formas de atuação nesse campo, fato que se evidenciou na realização da I Conferência Nacional de Segurança Pública, realizada no ano de 2009 (ZACHER, 2009, p. 50). Tanto que, atualmente, não se tem previsão para a realização de uma segunda conferência, o que demonstra as dificuldades de construção social da segurança pública, enquanto uma atividade da democracia. Pode-se falar, ainda, em agentes sociais que continuam fora desse debate, mas que pertencem institucionalmente ao sistema de justiça criminal, como é o caso das Defensorias Públicas. Zacher (2009) identifica que o campo da segurança pública, no contexto da redemocratização brasileira, não se abriu para a participação social, diferentemente de outras áreas do Estado, tais como saúde e educação. Essa característica dificulta a construção do entendimento da segurança como um direito social da cidadania. Atualmente, porém, parece haver uma aproximação, ainda tímida, da perspectiva da democracia participativa com a segurança pública.

Como exemplo, temos a constituição de fóruns e conselhos participativos sobre essa temática em algumas cidades brasileiras, como em Porto Alegre e no Rio de Janeiro. Essa formação insere-se no processo de ampliação da participação social possibilitado e experimentado a partir da abertura democrática, havendo no país hoje uma diversidade de instâncias participativas, que conformam uma esfera pública de discussão e tematização de 
assuntos de relevância social (AVRITZER, 2008, p. 44; COSTA, 2002, p. 15) ${ }^{12}$. Porém, o campo da segurança pública, somente recentemente se abre nesse sentido. É interessante notar que a literatura tradicional sobre participação social no Brasil deixa de fora o questionamento sobre a ausência dessa mesma participação social na segurança pública, pois, provavelmente, o fechamento institucional dessa atividade não permitiu a criação de uma percepção de que, assim como outras áreas do Estado, como saúde e educação, ela também necessita, para sua fiscalização, da participação popular. Sobre a participação na Segurança Pública, Cunha (2006) escreve que:

A gestão dos conflitos exige o estabelecimento de um modelo político participativo, nos quais os canais institucionais de deliberação coletiva (dimensão retórica e argumentativa) estejam abertos às experiências informais de comunicação e de aprendizagem surgidas no espaço heterogêneo do social. A construção de outros atributos e significados ao poder local, no final do século XX, suscitou a renovação de outro conceito muito caro à teoria democrática, a saber: o de esfera pública. Trata-se, portanto, de uma esfera que contempla a interação entre diversos grupos organizados da sociedade (organizações de classe, associações, movimentos sociais, etc.) É um espaço para o debate dos problemas coletivos da sociedade, diferenciando do debate do espaço público estatal (CUNHA, 2006, p. 43).

Ao demonstrarmos as transformações pelas quais vêm passando a segurança pública no país, nós pretendemos demonstrar, a partir da literatura analisada, como esse é um processo social de idas e vindas. Pretendemos contribuir para o debate que se coloca sobre essa temática nas ciências sociais para a realização efetiva de uma justiça de transição democrática, sem perder de vista a complexidade teórica e prática que o tema possui.

Ainda, duas observações finais impõem-se: primeira, a de que esse processo de questionamento e reformulação, a partir do compartilhamento de responsabilidade entre Estado e sociedade sobre a segurança, faz parte da crescente democratização da esfera pública brasileira com relação a essa atividade, verificada a partir da promulgação da Constituição de 1988 e, segundo, que a continuidade desses pretensos projetos de qualificação na repressão ao crime e de políticas de prevenção social da violência e das conflitualidades sociais atuais parecem mais viáveis em um paradigma de justiça social, e não de controle social penal de cunho exclusivamente punitivo, estigmatizante e criminalizante, orientado seletivamente para as classes sociais que experimentam, de forma cotidiana, a subcidadania brasileira.

\footnotetext{
${ }^{12}$ Segundo Avritzer (2008), o Orçamento Participativo em diversas cidades brasileiras, os conselhos de políticas públicas e os Planos Diretores Municipais compõe essa diversidade.
} 


\section{REFERÊNCIAS}

ADORNO, Sérgio. Exclusão socioeconômica e violência urbana. Revista Sociologias, Porto Alegre, v.4, n. 8, p. 84-135, 2002.

ALMEIDA, Alberto Carlos. A posse de Goulart: emergência da esquerda e solução de compromisso. Antropolítica: Revista contemporânea de Antropologia e Ciência Política, Niterói, n. 2, 1997, p. 39-59.

AVRITZER, Leonardo. Instituições participativas e desenho institucional: algumas considerações sobre a variação da participação no Brasil democrático. Revista Opinião Pública, Campinas, v. 14, n. 1, 2008, p. 43-64.

BAYLEY, David H. Padrões de policiamento. São Paulo: EDUSP, 2001.

BURGOS, Marcelo Bauman. Cidade, Territórios e Cidadania. Dados: Revista de Ciências Sociais, Rio de Janeiro, v. 48, n. 1, 2005, p. 189-222.

COSTA, Sérgio. As cores de Ercília: esfera pública, democracia, configurações pósnacionais. Belo Horizonte: Editora da UFMG, 2002.

CUNHA. Eduardo Pazinato da. Conselho Municipal de Justiça e Segurança: a experiência de gestão participativa da segurança em Porto Alegre. Trabalho de Conclusão de Curso. Faculdade de Direito da Pontifícia Universidade Católica do Rio Grande do Sul. Porto Alegre, 2006.

DREIFUSS, René. 1964: A conquista do Estado (ação política, poder e golpe de classe). Petrópolis: Vozes, 1981.

FERNANDES, Fábio Duarte. Ambivalência das políticas públicas de segurança pública: os governos Antônio Britto e de Olívio Dutra e os novos atores. Dissertação de Mestrado. Programa de Pós-graduação em Sociologia da Universidade Federal do Rio Grande do Sul. Porto Alegre. 2010.

FICO, Carlos. O regime militar no Brasil (1964-1985). São Paulo: Saraiva, 2004.

FICO, Carlos; FERREIRA, Marieta ; ARAUJO, Maria Paula ; QUADRAT, Samantha. Ditadura e Democracia na América Latina. Rio de Janeiro: Fundação Getúlio Vargas, 2008.

FREIRE, Moema Dutra. Paradigmas de segurança no Brasil: da ditadura aos nossos dias. Revista Brasileira de Segurança Pública, São Paulo, v. 3, nº 5, 2009, p. 100-114.

GAMALHO, Nola. Malocas e Periferia: a produção do Bairro Restinga. In: Ateliê Geográfico. Goiânia. Revista eletrônica UFG/IESA, n.2, 2010.

GOFFMAN, Erving. Estigma: notas sobre a manipulação da identidade deteriorada. Rio de Janeiro: LTC, 1978.

GOLDSTEIN, Herman. Policiando uma sociedade livre. São Paulo: EDUSP, 2003. 
HOBSBAWM, Eric. A era dos extremos. História do breve século XX. Presença. Lisboa: 1996.

KRUCHIN, Mariana Kiefer. Análise da introdução de um novo paradigma em segurança pública no Brasil. Revista Brasileira de Segurança Pública, São Paulo, v. 7, nº 1, 2013, p. 4056.

MISSE, Michel. Crime, sujeito e sujeição criminal: aspectos de uma contribuição analítica sobre a categoria “bandido". Lua Nova, São Paulo, n. 79, 2010, p. 15-38.

NUMMER, Fernanda. "Ser Brigadiano" ou "trabalhar na Brigada": Estilos de vida entre soldados da Brigada Militar. Tese de Douturado. Programa de Pós-graduação em Antropologia Social da Universidade Federal do Rio Grande do Sul. Porto Alegre, 2010.

OLIVEIRA, Antonio. Os policiais podem ser controlados?. Revista Sociologias, Porto Alegre, ano 12, n. 23, 2010, p. 142-174.

OLIVEIRA, Lívio Silva de. Os militares e a redemocratização no Brasil. In: I Congresso Internacional de Estudos das Américas, Rio de Janeiro, 2008.

PINHEIRO, Paulo Sérgio. Violência, crime e sistemas policiais em países de novas democracias. Revista Tempo Social, São Paulo, 1997, nº 9, v. 1, p. 43-52.

SOUZA, Jessé. A modernização seletiva: uma reinterpretação do dilema brasileiro. Brasília: Editora da UnB, 2000.

SOUZA, Jessé. (Não) Reconhecimento e subcidadania, ou o que é "ser gente"?. Revista Lua Nova, São Paulo, nº 59, 2003, p. 51-74.

TAVARES-DOS-SANTOS, José Vicente; TEIXEIRA, Alex Niche (Orgs.). Conflitos sociais e perspectivas da paz. Porto Alegre: Tomo Editorial. 2012.

TAVARES-DOS-SANTOS, José Vicente. Violências, América Latina: a disseminação de formas de violência e os estudos sobre conflitualidades. Revista Sociologias, Porto Alegre, ano $4, n^{\circ} 8,2002$, p. 16-32.

TAVARES-DOS-SANTOS, José Vicente. Violências e Conflitualidades. Porto Alegre: Tomo Editorial, 2009.

TAVARES-DOS-SANTOS, José Vicente (Org). Violência em tempos de globalização. São Paulo: Hucitec, 1999.

WIEVIORKA, Michel. O novo paradigma da violência. Revista Tempo Social, São Paulo, n 9 , v. 1, 1997, p. 5-41.

ZACHER, Laura. A Segurança Pública como direito: limites e possibilidades da participação social em conselhos de segurança pública em perspectiva comparada. Trabalho de Conclusão de Curso. Instituto de Filosofia e Ciências Humanas da Universidade Federal do Rio Grande do Sul. Porto Alegre, 2009. 
REVISTA ALAMEDAS

Vol. 5, n. 1, 2017

e-ISSN 1981-025

18 